(C) 2017, Elsevier. Licensed under the Creative Commons Attribution-NonCommercial-NoDerivatives 4.0 International http://creativecommons.org/licenses/by-nc-nd/4.0/

The role of multicultural and colorblind ideologies and typicality in imagined contact interventions

Emilio Paolo Visintin ${ }^{1}$, Michèle Denise Birtel ${ }^{2}$, Richard J. Crisp ${ }^{3}$

1. University of Lausanne (Switzerland)

2. University of Surrey (United Kingdom)

3. Aston Business College (United Kingdom)

Corresponding author: Emilio Paolo Visintin, Institute of Psychology, University of Lausanne,

Bâtiment Géopolis, 1015 Lausanne, Switzerland. Telephone number: +41216923770. Fax number:

+41216923215. E-mail: emiliop.visintin@gmail.com

The authors received no financial support for this study.

Word count: 4,976 words

Abstract word count: 167 words 


\begin{abstract}
Recent studies have demonstrated that simply imagining a positive interaction with an outgroup member reduces prejudice, especially if the outgroup member is typical of the whole outgroup. In this research, we tested how a multicultural vs. colorblind mindset might impact the efficacy of imagined contact with a typical or atypical outgroup member. Specifically, we tested the interactive effects between ideologies (multiculturalism vs. colorblindness) and the typicality of the outgroup member (typical vs. atypical) in the imagined encounter. Results revealed that participants exposed to the multicultural ideology who imagined an encounter with an atypical outgroup member expressed fewer positive perceptions (warmth and competence) toward both primary and secondary outgroups compared with respondents exposed to the multicultural ideology who imagined an interaction with a typical outgroup member, and compared with respondents exposed to a colorblind ideology (irrespective of typicality of the outgroup member). The study highlights the importance of considering the interaction between cultural ideologies and typicality during intergroup contact when designing interventions aimed at promoting positive intergroup perceptions.
\end{abstract}

Keywords: Multiculturalism, Colorblindness, Imagined Contact, Typicality, Secondary Transfer Effect. 


\section{The role of multicultural and colorblind ideologies and typicality in imagined contact interventions}

Migration, ethnic and cultural diversity, and their impact on societies and workplaces are contemporary debated within many western societies (Green \& Staerklé, 2013). Diversity research has examined the potential of multiculturalism and colorblindness as strategies and policies to promote positive intergroup relations and harmony. There is a strong debate regarding which of these two ideologies is more effective in reducing intergroup bias among social psychologists (e.g., Guimond, de la Sablonnière, Nugier, 2014; Sasaki \& Vorauer, 2013) and in the political discourse, as for example David Cameron, the former UK prime minister, declared in 2011 that multiculturalism has failed (BBC News, 2011). Although there is a wealth of studies considering the effects of exposure to these ideologies (e.g., Richeson \& Nussbaum, 2004; Wolsko, Park, Judd, \& Wittenbrink, 2000), research is only beginning to test how a multicultural or colorblind mindset impacts the effectiveness of prejudice-reduction interventions based on intergroup contact theory (Allport, 1954; Pettigrew \& Tropp, 2011). With this study, we aimed at filling this gap by investigating how exposure to a specific form of diversity experience (multiculturalism vs. colorblindness) can impact the effectiveness of the imagined contact intervention (Crisp \& Turner, 2012).

\section{Multicultural and Colorblind Ideologies}

Multiculturalism and colorblindness are ideologies aimed at promoting positive intergroup relations and harmony. The multiculturalism approach stresses the importance of recognizing cultural differences between groups and giving value to these differences (e.g., Guimond, 2010; Verkuyten, 2005). The colorblindness approach, on the other hand, sustains that the specific characteristics of groups should be abandoned in order to treat people equally as individuals rather than as members of particular groups (e.g., Plaut, 2010; see also Miller, 2002). Although both ideologies are predicted to promote tolerance, research considering their impact on prejudice- 
reduction has provided mixed results (for reviews see Park \& Judd, 2005; Rosenthal \& Levy, 2010; Sasaki \& Vorauer, 2013). While some studies have found that both multiculturalism and colorblindness are associated to positive outgroup attitudes (e.g., Levin et al., 2012), other studies have suggested also negative effects of these ideologies on prejudice (for multiculturalism see e.g., Morrison, Ybarra, \& Plaut, 2010; for colorblindness see e.g., Vorauer, Gagnon, \& Sasaki, 2009) Notable is the finding by Wolsko and colleagues (2000) that participants primed with multicultural ideologies report positive feelings toward minorities, but simultaneously heightened awareness of stereotypes associated with the group.

As proposed by Crisp and Turner (2011), diversity experiences can influence how people experience and react to subsequent events. This suggests that a multicultural or a colorblind mindset might influence responses to experiences such as intergroup contact. Specifically, a multicultural mindset might lead to focus on differences during intergroup encounters (Wolsko et al., 2010), while a colorblind mindset might lead to focus on similarities (Rosenthal \& Levy, 2010). In this study, we will examine how the focus on differences vs. on similarities induced by priming of ideologies may impact the imagined intergroup effect.

\section{Imagined Intergroup Contact and Typicality}

A growing body of research has demonstrated the benefits of mental imagery in various areas such as health and personality psychology, consumer research, clinical therapy, and sports (see Crisp, Birtel, \& Meleady, 2011). Crisp and Turner (2012) have thus argued that these benefits can also extend to the prejudice domain, and, in particular, that imagery related to intergroup contact can promote tolerance and positive intergroup relations. Research has now widely supported the beneficial effects of imagining a positive encounter with an outgroup member on prejudice reduction and positive intergroup behavior (e.g., Husnu \& Crisp, 2010, 2015; Vezzali, Capozza, Giovannini, \& Stathi, 2012; for a meta-analysis see Miles \& Crisp, 2014). For example, Husnu and Crisp (2015) found that Turkish Cypriots who imagined a pleasant encounter with Greek Cypriots 
reported more positive outgroup attitudes compared to Turkish Cypriots who imagined walking outdoors. In this vein, Brambilla, Ravenna, and Hewstone (2012) examined the effects of imagined contact with members of outgroups that differ in warmth and competence stereotypes derived from the stereotype content model (SCM; Fiske, Cuddy, Glick, \& Xu, 2002). Specifically, Italian students were invited to imagine an encounter with a member of an immigrant group which is stereotyped in Italian society as warm but incompetent (Peruvians), as competent but cold (Chinese), as both incompetent and cold (Albanians), or as both competent and warm (Canadians). The authors found that imagined contact was effective in improving the stereotype that was negative for each specific outgroup, i.e. imagined contact improved competence perceptions of Peruvians, warmth perceptions of Chinese, and competence and warmth perceptions of Albanians.

Recent studies have also identified characteristics of the imagined contact manipulation that enhance the efficacy of this intervention. Notable for an optimal imagined contact situation is the mutual intergroup differentiation model (MIDM; Hewstone \& Brown, 1986), proposing that intergroup salience and typicality of the outgroup member during the contact situation promote the generalization of the beneficial effects of contact from the outgroup member involved in the contact situation to the whole outgroup (see also Brown \& Hewstone, 2005). Specifically, typicality refers to characteristics of the outgroup member that are likely to enhance the perception of the outgroup member as typical and representative of own group. When an intergroup encounter happens with an outgroup member who is typical and representative of own group, the risk of subtyping is lower, i.e. of considering the positive characteristics of the outgroup member discovered during intergroup contact as an exception, leaving unaltered the evaluation of the whole outgroup (see Richards \& Hewstone, 2000).

An experiment by Stathi, Crisp, and Hogg (2011, Study 3) investigated the role of typicality of the outgroup member during an imagined contact intervention. British students were invited to imagine an encounter with a British Muslim described as dressing in a traditional way, avoiding 
alcohol, and practicing strictly Islamic religion (typical British Muslim) or with a British Muslim described as dressing in Western clothes, drinking alcohol, and not practicing strictly Islamic religion (atypical British Muslim). The authors found that imagined contact with a typical British Muslim increased contact self-efficacy compared to imagined contact with an atypical British Muslim (see also Pagotto, Visintin, De Iorio, \& Voci, 2013 for an imagined contact experiment applying the MIDM).

Building on the MIDM and findings by Stathi et al. (2011, Study 3), we manipulated the degree of typicality of the outgroup member during the imagined intergroup encounter and extended the study by Stathi et al. considering the role of ideologies in shaping the typicality effect.

\section{The Current Study}

In this experimental study we tested the interactive effects of priming a multicultural vs. colorblind ideology (Wolsko et al., 2000) and of imagining contact with a typical vs. atypical outgroup member (Stathi et al., 2011, Study 3). Outgroup attitudes were measured as warmth and competence perceptions (SCM; Fiske et al., 2002). While previous research on imagined contact has mainly focused on prejudice and future contact intentions as outcomes, only one study suggested that imagined contact can improve warmth and competence perceptions (Brambilla et al., 2012). We extended this study by testing the role of ideologies and of typicality.

We argue that the multicultural ideology, being associated with stereotyping and subtyping (Wolsko et al., 2000), could curb the effects of imagined contact. Specifically, respondents in a multicultural mindset should report more positive outgroup perceptions after imagined contact with an outgroup member typical of their group than after imagined contact with an outgroup member atypical of their group, given that typicality helps avoiding subtyping (Brown \& Hewstone, 2005). In contrast, for participants in a colorblind mindset atypicality of the outgroup member might not hamper the imagined contact effect, given that colorblindness per se promotes focusing on similarities (Rosenthal \& Levy, 2010) and thus generalization. The primed ideology should thus 
make a difference when outgroup typicality is low: Specifically we expected, among respondents who imagined an encounter with an atypical outgroup member, more positive outgroup perceptions for those primed with the colorblind ideology than for those primed with the multicultural ideology.

We further examined whether our experimental manipulations impacted also perceptions toward outgroups not involved in the imagined encounter, to test whether cultural ideologies and imagined contact can be combined to design interventions aimed at promoting generalized positive outgroup perceptions. Our reasoning is based on literature on the generalized positive effects of intergroup contact on intergroup relations (see Pettigrew \& Tropp, 2011). For example, Dhont, Van Hiel, and Hewstone (2014) found that intergroup contact is associated to reduced preference for hierarchical intergroup relations and group-based inequality, i.e. to lower social dominance orientation (Sidanius \& Pratto, 1999). Importantly, our expectation is corroborated by literature on secondary transfer effect (STE), that is, the prejudice reduction following the encounter with a member of a (primary) outgroup toward a (secondary) outgroup not involved in the intergroup encounter (Pettigrew, 2009). Previous research has found wide support for the STE (Lolliot et al., 2012; Tausch et al., 2010; for imagined contact see Harwood, Paolini, Joyce, Rubin, \& Arroyo, 2011) and further suggested that STEs occur mainly toward secondary outgroups perceived as similar to the primary outgroup (Pettigrew, 2009). For example, Harwood et al. (2011) found that positive imagined contact with an illegal immigrant was effective in improving American students' attitudes toward illegal immigrants and toward outgroups perceived as similar to illegal immigrants, but not toward dissimilar outgroups. Thus, we conducted a pretest to choose two groups perceived as similar and two groups perceived as dissimilar to the primary outgroup (British Muslims).

We expected for perceptions toward uninvolved outgroups a pattern similar to the one for perceptions toward the primary outgroup (less positive outgroup perceptions for respondents in the multiculturalism-atypical condition compared to those in the other experimental conditions). The experimental manipulations should impact perceptions especially toward uninvolved outgroups 
perceived as similar to the outgroup of the imagined interaction (Harwood et al., 2011; Pettigrew, 2009).

\section{Method}

\section{Pretest}

We first conducted a pretest to detect groups who were perceived as similar or dissimilar to the primary outgroup (British Muslims), adapting the procedure of Harwood et al. (2011). We asked 12 undergraduate students to rank 20 groups in terms of how similar to British Muslims they were $(1=$ most similar $; 20=$ least similar $)$. Reliability across the 12 raters was good $($ Cronbach's alpha $=$

.82). We then selected the two most similar groups, namely Moroccans $\left(M_{\text {similarity }}=4.75, S D=3.65\right)$ and Asians $\left(M_{\text {similarity }}=5.92, S D=6.91\right)$, and two of the least similar groups, namely physically disabled people $\left(M_{\text {similarity }}=14.08, S D=3.82\right)$ and people with schizophrenia $\left(M_{\text {similarity }}=15.33, S D\right.$ $=3.28)$.

\section{Participants}

Initially, 88 students of a university located in South-Eastern England participated to the study (13 male and 75 female, $\left.M_{a g e}=19.99, S D=3.23\right)$. We then excluded from further analyses data of Asian respondents $(n=10)$, since Asians were one of the target groups participants had to evaluate, data of participants who explicitly declared previous knowledge of the imagined contact paradigm $(n=1)$, and data of participants who displayed zero variation on all the measures of the questionnaire $(n=1) .{ }^{1}$ The final sample consisted of 76 students $\left(13\right.$ male and 63 female, $M_{\text {age }}=$ 19.97, $S D=3.20$ ). Participants were randomly allocated to one of the four conditions of a 2 (Ideology: colorblind vs. multicultural) $\times 2$ (Typicality: typical outgroup member vs. atypical outgroup member) experimental design. They took part in the study for partial course credit.

\section{Procedure}

The study received ethical approval by the local institutional research and ethics committee. Participants completed the study online. We first manipulated multiculturalism vs. colorblindness, 
and then imagined contact with a typical vs. atypical outgroup member. The diversity ideologies experimental manipulations were adapted from Wolsko et al. (2000) and from Richeson and Nussbaum (2004). Participants first read an essay regarding the benefits of adopting a multicultural (or colorblind) perspective. The multiculturalism essay suggested that intergroup harmony can be achieved appreciating diversity and recognizing and accepting each group's positive and negative qualities, while the colorblindness essay stressed the importance of ignoring ethnic divisions and learning to see others simply as fellow human beings. Next, to strengthen the effects of the manipulation, participants were asked to list five reasons why adopting a multicultural (or colorblind) perspective would benefit the UK. Finally and again as a reinforcement of the manipulation, participants were proposed a list of 21 possible reasons, allegedly written by other students, for adopting a multicultural vs. a colorblind approach to diversity in the UK. These reasons differed between the multiculturalism and colorblindness conditions, and matched the content of the respective ideology (see Wolsko et al., 2000). Participants were asked to select the answers similar to their opinion.

Then, participants received the imagined contact manipulation: They were asked to imagine meeting for the first time an unknown British Muslim who is typical vs. atypical of British Muslims in general (see Stathi et al., 2011). Specifically, participants in the typical imagined contact condition were provided these instructions: "We would like you to take a minute to imagine yourself meeting a British Muslim stranger for the first time. Imagine that this person is a typical Muslim, he/she dresses in a traditional way, avoids alcohol, reads the Koran and prays five times a day. Imagine that the interaction is relaxed, positive and comfortable. Imagine that you learn about the life and experiences of your conversation partner." Participants in the atypical condition instead read: "We would like you to take a minute to imagine yourself meeting a British Muslim stranger for the first time. Imagine that this person is a not a typical Muslim, he/she dresses in "western" clothes, drinks alcohol, eats pork and does not pray regularly. Imagine that the interaction is 
relaxed, positive and comfortable. Imagine that you learn about the life and experiences of your conversation partner." In both conditions, they then had to describe what they had imagined.

Warmth and competence perceptions were measured separately for the five groups (British Muslims, Moroccans, physically disabled people, Asians, and people with schizophrenia). Respondents had to rate each group on three warmth (friendly, likable, and helpful) and on three competence (intelligent, competent, and capable) traits with response scales from 1 (not at all) to 7 (very much) (see Brambilla et al., 2012). A composite warmth score and a composite competence score was computed by the mean of these items for each of the target groups, with higher scores indicating greater warmth and competence (Cronbach's alphas from .78 to .96).

\section{Results}

Table 1 reports means and standard deviations of the dependent variables as a function of the ideology and of typicality of the imagined outgroup member. To determine whether there is an interaction between ideology priming and typicality on competence and warmth perceptions, we computed two 2 (multicultural vs. colorblind ideology) $\times 2$ (typical imagined contact vs. atypical imagined contact) multivariate analyses of variance (MANOVAs), one for competence and one for warmth toward all five target groups as dependent variables.

\section{Competence}

There were no main effects of ideology or typicality on competence perceptions, $F(5,68)$ values $<0.80, p s>.555, \eta_{p}^{2}<.055$. Importantly, the predicted interaction between ideology and typicality was marginally significant, $F(5,68)=2.15, p=.070, \eta^{2}=.136$.

Primary outgroup. Looking at the univariate statistics for the target group of the imagined contact manipulation (British Muslims), we found a marginally significant main effect of typicality, $F(1,72)=3.49, p=.066, \eta_{\mathrm{p}}^{2}=.046$. British Muslims were perceived as more competent after imagined contact with a typical outgroup member $(M=5.88, S D=0.93)$ than after imagined contact with an atypical outgroup member $(M=5.48, S D=1.06)$. No main effect of the ideology 
emerged, $F(1,72)=0.32, p=.576, \eta^{2} \mathrm{p}=.004$. More importantly, the predicted ideology $\times$ typicality interaction was significant, $F(1,72)=4.06, p=.048, \eta^{2}{ }_{p}=.053$. Looking at the simple effects, competence perceptions were higher in the multiculturalism-typical than in the multiculturalismatypical condition, $F(1,72)=7.13, p=.009, \eta_{\mathrm{p}}^{2}=.090$, while no difference emerged between the colorblindness-typical and the colorblindness-atypical conditions, $F(1,72)=0.01, p=.915, \eta_{\mathrm{p}}^{2}=$ .000. Furthermore, in the atypical imagined contact condition, competence perceptions of British Muslims were higher, at a marginally significant level, in the colorblindness compared to the multiculturalism condition, $F(1,72)=3.53, p=.064, \eta^{2}=.047$, while there were no differences between ideologies in the typical imagined contact condition, $F(1,72)=1.00, p=.321, \eta_{\mathrm{p}}^{2}=.014$.

Secondary outgroups. For Moroccans and Asians, there were no main effects, $F(1,72)$ values $<2.68, p s>.105, \eta_{p}^{2}<.036$, but a significant ideology $\times$ typicality interaction, $F_{\text {Moroccans }}(1,72)=4.60, p=.035, \eta_{\mathrm{p}}^{2}=.060, F_{\text {Asians }}(1,72)=4.84, p=.031, \eta_{\mathrm{p}}^{2}=.063$. Looking at simple effects, competence perceptions were higher in the multiculturalism-typical than in the multiculturalism-atypical condition, $F_{\text {Moroccans }}(1,72)=6.76, p=.011, \eta^{2} \mathrm{p}=.086, F_{\text {Asians }}(1,72)=$ $6.40, p=.014, \eta^{2}{ }_{p}=.082$, while no difference emerged between the colorblindness-typical and the colorblindness-atypical conditions, $F(1,72)$ values $<0.28, p s>.602, \eta^{2}$ values $<.004$.

Furthermore, in the atypical imagined contact condition, Moroccans and Asians were perceived more competent in the colorblindness than in the multiculturalism condition, $F_{\text {Moroccans }}(1,72)=4.64$, $p=.035, \eta_{\mathrm{p}}^{2}=.060$, and $F_{\text {Asians }}(1,72)=4.84, p=.031, \eta_{\mathrm{p}}^{2}=.063$, while there were no differences between ideologies in the typical imagined contact condition, $F(1,72)$ values $<0.90, p s>.345, \eta^{2}$ p values $<.013$

Regarding competence perceptions of physically disabled people and people with schizophrenia, no significant main effects or interactions emerged, $F(1,72)$ values $<2.59$, $p s>.112$, $\eta_{\mathrm{p}}^{2}<.035$. 
In summary, competence perceptions of British Muslims (the primary outgroup), Moroccans and Asians were lower in the multiculturalism-atypicality condition compared to the other experimental conditions.

\section{Warmth}

Repeating the same analyses for warmth, there were no main effects of ideology or typicality on warmth perceptions, $F(5,68)$ values $<1.59, p s>.174, \eta^{2}$ p values $<.105$. The predicted interaction between ideology and typicality was instead significant, $F(5,68)=3.89, p=.004, \eta^{2} \mathrm{p}=$ .222 .

Primary outgroup. Looking at the univariate statistics for the primary outgroup (British Muslims), we found no significant main effects or interaction on warmth perceptions toward British Muslims, $F(1,72)$ values $<1.00, p \mathrm{~s}>.321, \eta_{\mathrm{p}}^{2}$ values $<.014$

Secondary outgroups. However, we found that the experimental manipulations affected warmth perceptions toward Moroccans and physically disabled people. There were main effects of typicality for Moroccans, $F(1,72)=4.02, p=.049, \eta_{\mathrm{p}}^{2}=.053$, and physically disabled people, $F(1,72)=3.15, p=.080, \eta^{2} \mathrm{p}=.042$. Both Moroccans and physically disabled people were perceived as warmer after imagined contact with a typical British Muslim $\left(M_{\text {Moroccans }}=5.77, S D=0.91\right.$, $\left.M_{\text {disabled }}=5.80, S D=0.89\right)$ than after imagined contact with an atypical British Muslim $\left(M_{\text {Moroccans }}=\right.$ $\left.5.35, S D=1.05, M_{\text {disabled }}=5.39, S D=1.14\right)$. There were no main effects of the ideology, $F(1,72)$ values $<1.95, p \mathrm{~s}>.167, \eta_{\mathrm{p}}^{2}$ values $<.026$. More importantly, the predicted interaction between ideology and typicality was significant for the attribution of warmth toward Moroccans, $F(1,72)=$ $6.43, p=.013, \eta_{\mathrm{p}}^{2}=.082$, and marginally significant for the attribution of warmth toward physically disabled people, $F(1,72)=3.41, p=.069, \eta^{2} \mathrm{p}=.045$. A test of the simple effects showed that perceptions of Moroccans and of physically disabled people as warm were higher in the multiculturalism-typical than in the multiculturalism-atypical condition, $F_{\text {Moroccans }}(1,72)=9.74, p=$ $.003, \eta_{\mathrm{p}}^{2}=.119, F_{\text {disabled }}(1,72)=6.19, p=.015, \eta_{\mathrm{p}}^{2}=.079$. No difference emerged between the 
colorblindness-typical and the colorblindness-atypical conditions, $F(1,72)$ values $<0.15, p s>.700$, $\eta_{\mathrm{p}}^{2}$ values $<.002$. Furthermore, in the atypical imagined contact condition, Moroccans and physically disabled people were perceived as warmer in the colorblindness than in the multiculturalism condition, $F_{\text {Moroccans }}(1,72)=5.37, p=.023, \eta_{\mathrm{p}}^{2}=.069, F_{\text {disabled }}(1,72)=5.58, p=$ $.021, \eta_{\mathrm{p}}^{2}=.072$, while there were no differences between ideologies in the typical imagined contact condition, $F(1,72)$ values $<1.69, p s>.197, \eta^{2}$ values $<.023$.

Regarding warmth perceptions of Asians and people with schizophrenia, no significant main effects or interaction emerged, $F(1,72)$ values $<2.28, p s>.135, \eta^{2}$ values $<.031$.

In summary, warmth perceptions of Moroccans and physically disabled people were lower for respondents exposed to the multicultural manipulation who imagined an encounter with an atypical British Muslim compared to respondents in the other experimental conditions.

\section{Discussion}

Our study examined whether priming a multicultural or colorblind ideology impacts the effectiveness of the imagined contact intervention with a typical or atypical outgroup member on warmth and competence perceptions toward the outgroup involved in the imagined encounter and toward uninvolved outgroups. Although not all the dependent variables were affected by the experimental manipulations, a relatively consistent pattern of results emerged: Positive outgroup perceptions were lower in the multiculturalism-atypical condition compared to the other experimental conditions. We found this for competence perceptions toward the primary outgroup (British Muslims) and two uninvolved outgroups (Moroccans and Asians), and for warmth perceptions toward two uninvolved outgroups (Moroccans and physically disabled people).

Taken together, our results suggest that imagined contact improves outgroup perceptions after the priming of a multicultural ideology when the outgroup member involved in the imagined interaction is typical of their group compared to an imagined interaction with an atypical outgroup member. Typicality of the outgroup member involved in the imagined encounter does not make a 
difference after the priming of a colorblind ideology. The finding that respondents exposed to a multicultural prime and who imagined an interaction with an atypical outgroup member exhibited fewer positive outgroup perceptions than participants in the other experimental conditions suggests that, in line with our hypotheses, a multicultural mindset may lead to focus on differences (Wolsko et al., 2000), and thus curb the imagined contact effect. However, when imagining an encounter with a typical outgroup member, the role of typicality in promoting generalization effects (Brown \& Hewstone, 2005) counteracts the subtyping caused by a multicultural prime. When respondents are in a colorblind mindset, instead, the typicality of the outgroup member seems not necessary for fostering positive outgroup perceptions, because the colorblindness per se leads to focus on similarities (Rosenthal \& Levy, 2010), favoring generalization effects.

Some of our hypotheses were instead not confirmed. Unexpectedly, warmth perceptions toward the primary group (British Muslims) did not differ between the experimental conditions. It is possible that, for this specific group, warmth perceptions are particularly resistant to change, and that a single session experimental manipulation is not enough to change this stereotype.

It is further remarkable that we found the predicted pattern on competence perceptions toward the two similar groups (Moroccans and Asians) but not toward the two dissimilar groups (Moroccans and physically disabled people). For warmth, instead, we found the predicted pattern on one similar (Moroccans) and one dissimilar (physically disabled people) group. The role of similarity on generalization of outgroup perceptions was thus found only for competence but not for warmth. In our view, this could be due to different types of stereotypes associated with the outgroups considered in our study. Indeed, British Muslims, Asians, and Moroccans are likely to be perceived as similar more on competence than on warmth traits, as members of these groups might be considered as non-British people living in the UK often because of working opportunities.

Finally, we did not find any effect on warmth and competence perceptions toward people with schizophrenia. Although previous research has found that imagined intergroup contact with 
people with schizophrenia can improve affective attitudes and foster future contact intentions (Stathi, Tsanilla, \& Crisp, 2012; West, Holmes, \& Hewstone, 2011, Studies 3 and 4, but cf. West et al., 2011, Studies 1 and 2), it is possible that warmth and competence perceptions of this severely stigmatized group are less malleable than those of the other outgroups considered in this study.

\section{Implications, Limitations, and Future Directions}

From our study we can outline suggestions for structuring imagined contact interventions that could be implemented, for example, in schools (see e.g., Vezzali et al., 2012), with the aim of promoting positive outgroup perceptions between ethno-cultural groups. Specifically, presenting the outgroup member of the imagined interaction as typical of own group could be beneficial for the effectiveness of the imagined contact intervention (see also Stathi et al., 2011). Our results also advise that a focus on similarities and a colorblind mindset might improve the imagined contact effect, especially when typicality is low or not salient. In sum, our results suggest that, to maximize the imagined contact effect, at least one feature between typicality of the imagined outgroup member and a focus on intergroup similarities should be emphasized during imagined contact interventions. Our study also points out to the potentially broad impact of interventions combining ideologies and imagined contact, as our experimental manipulations did not impact perceptions only toward the primary outgroup but also toward uninvolved outgroups.

Despite the novelty of our findings, we have to acknowledge some limitations of our study. First, we did not include a control condition in which we did not manipulate diversity ideologies and imagined intergroup contact. Thus, we can only speculate that diversity ideologies and imagined contact were associated to positive outgroup stereotypes, and we cannot univocally conclude that there were improvements of warmth and competence outgroup perceptions. However, our interpretation is based on previous research showing that both multicultural and colorblind ideologies can reduce ingroup bias compared to control conditions (Wolsko et al., 2000, Study 1) and that imagined contact can effectively reduce prejudice compared to control imagination tasks 
(Miles \& Crisp, 2014). Nevertheless, future research should aim at replicating and extending our study by including control conditions with no manipulation of diversity ideologies and of imagined contact.

Second, the sample size of our experiment, with 16 to 20 respondents by experimental condition, is quite low, even if in line with previous research on imagined intergroup contact (e.g., Husnu \& Crisp, 2010, Study 1; Stathi et al., 2011) and on diversity ideologies (Richeson \& Nussbaum, 2004). This is likely to explain why several effects were only marginally significant (with $p$ s $>.05$ and $<.10$ ). Future research should replicate our findings with bigger samples.

Third, even if our experimental manipulations were based on previous prominent research (Richeson \& Nussbaum, 2004; Wolsko et al., 2010 for diversity ideologies; Stathi et al., 2011 for typicality during imagined contact), there could be some confounding variables embedded in the manipulations, and consequently some alternative interpretations of the findings. The colorblindness experimental manipulation stressed the importance of treating people as human beings irrespective of differences. This might have primed the superordinate category of humanity, which should be associated to intergroup tolerance and to tolerant norms about intergroup relations (Albarello \& Rubini, 2012). The positive outgroup perceptions when primed with the colorblind manipulation irrespective of typicality might then be due to the priming of the superordinate category that is humanity, instead of the focus on similarities that is implied in the colorblindness ideology. Regarding the typicality experimental manipulation, it is possible that the typical British Muslim described in the imagined contact scenario also represents a stereotypical British Muslim, while the atypical British Muslim could represent a counter stereotypical British Muslim. A possible alternative interpretation of our findings would then be that multiculturalism is not associated to positive outgroup perceptions when combined with imagined contact with individuals not conforming to pre-existing stereotypes. While with our study we cannot rule out these alternative explanations, we encourage future research to disentangle these issues. 
Fourth, our study considered as dependent variables positive perceptions or stereotypes of warmth and competence toward minority groups. However, positive stereotypes might have undesirable consequences. Minority members who are the target of positive stereotypes might perceive themselves at risk of being target also of negative stereotypes and might perceive the counterpart as prejudiced (Siy \& Cheryan, 2016). Intergroup harmony following intergroup contact has also been associated to minority members' reduced willingness to engage in collective action to improve their situation (see Dixon, Levine, Reicher, \& Durrheim, 2012). Future research should investigate the complexity of intergroup dynamics by considering the point of view of both majority and minority groups, and examine consequences of ideologies and of imagined contact for all the involved groups.

Future research should also examine the mechanisms that underlie the effects of the interplay between diversity ideologies and typicality on outgroup perceptions. Mediators could relate to affective and emotional responses to outgroups and to tolerant norms about intergroup relations (see Crisp, Husnu, Meleady, Stathi, \& Turner, 2010 for a discussion on mediators of imagined contact effects). Furthermore, future research should include measures of direct contact with the primary and uninvolved outgroups to examine whether the emerged effects occur over and above the effects of direct contact. Finally, future research should consider the effects of the interplay between diversity ideology and typicality on behavioral intentions and actual behavior.

\section{Conclusions}

In culturally diverse societies, the need to promote positive intergroup attitudes and perceptions has attracted attention of researchers who have investigated the impact of diversity ideologies (Guimond et al., 2014; Wolsko et al., 2000) and of intergroup contact interventions (Crisp \& Turner, 2012; Pettigrew \& Tropp, 2011). Our study shows that the two approaches could be considered simultaneously to maximize the efficacy of programs aimed at fostering intergroup 
harmony. We encourage future research to further examine the interplay between different prejudice-reduction strategies to discover how they can be combined to capitalize on their effects. 


\section{Footnotes}

1. Unfortunately, we did not ask respondents their religious affiliation, so we cannot exclude respondents who are British Muslims from data analysis. Based on 2011 Census data, the Muslim population in the district of data collection (Canterbury) was $1.2 \%$, suggesting that a low number of respondents should be Muslim. 


\section{References}

Albarello, F., \& Rubini, M. (2012). Reducing dehumanization outcomes towards Black people: The role of multiple categorization and of human identity. European Journal of Social Psychology, 42, 875-882.

Allport, G. (1954). The nature of prejudice. Reading, MA: Addison-Wesley.

BBC News (2011, 5 February). State multiculturalism has failed, says David Cameron. Retrieved from BBC News website: http://www.bbc.co.uk/news/uk-politics-12371994

Brambilla, M., Ravenna, M., \& Hewstone, M. (2012). Changing stereotype content through mental imagery: Imagining intergroup contact promotes stereotype change. Group Processes \& Intergroup Relations, 15, 305-315.

Brown, R., \& Hewstone, M. (2005). An Integrative Theory of Intergroup Contact. Advances in Experimental Social Psychology, 37, 255-343.

Crisp, R. J., Birtel, M. D., \& Meleady, R. (2011). Mental simulations of social thought and action: Trivial tasks or tools for transforming social policy? Current Directions in Psychological Science, 20, 261-264.

Crisp, R. J., Husnu, S., Meleady, R., Stathi, S., \& Turner, R. N. (2010). From imagery to intention: A dual route model of imagined contact effects. European Review of Social Psychology, 21, $188-236$.

Crisp, R. J., \& Turner, R. N. (2011). Cognitive adaptation to the experience of social and cultural diversity. Psychological Bulletin, 137, 242-266.

Crisp, R. J., \& Turner, R. N. (2012). The imagined contact hypothesis. Advances in Experimental Social Psychology, 46, 125-182.

Dhont, K., Van Hiel, A. \& Hewstone, M. (2014). Changing the ideological roots of prejudice: Longitudinal effects of ethnic intergroup contact on social dominance orientation. Group Processes \& Intergroup Relations, 17, 27-44. 
Dixon, J., Levine, M., Reicher, S., \& Durrheim, K. (2012). Beyond prejudice: Are negative evaluations the problem and is getting us to like one another more the solution? Behavioral \& Brain Sciences, 35, 411-425.

Fiske, S. T., Cuddy, A. J., Glick, P., \& Xu, J. (2002). A model of (often mixed) stereotype content: Competence and warmth respectively follow from perceived status and competition. Journal of Personality and Social Psychology, 82, 878-902.

Green, E. G. T., \& Staerklé, C. (2013). Migration and multiculturalism. In L. Huddy, D. O. Sears, \& J. Levy (Eds.), Oxford handbook of political psychology (pp. 852-889). Oxford, UK: Oxford University Press.

Guimond, S. (2010). Psychologie sociale: Perspective Multiculturelle. [Social psychology : A multicultural perspective]. Wavre, Belgique: Mardaga.

Guimond, S., de la Sablonnière, R., \& Nugier, A. (2014). Living in a multicultural world: Intergroup ideologies and the societal context of intergroup relations. European Review of Social Psychology, 25, 142-188.

Harwood, J., Paolini, S., Joyce, N., Rubin, M., \& Arroyo, A. (2011). Secondary transfer effects from imagined contact: Group similarity affects the generalization gradient. British Journal of Social Psychology, 50, 180-189.

Hewstone, M., \& Brown, R. (1986). Contact is not enough: An intergroup perspective on the contact hypothesis. In M. Hewstone \& R. Brown (Eds.), Contact and conflict in intergroup encounters (pp. 1-44). Oxford, UK: Blackwell.

Husnu, S., \& Crisp, R. J. (2010). Elaboration enhances the imagined contact effect. Journal of Experimental Social Psychology, 46, 943-950.

Husnu, S., \& Crisp, R. J. (2015). Perspective-taking mediates the imagined contact effect. International Journal of Intercultural Relations, 44, 29-34. 
Levin, S., Matthews, M., Guimond, S., Sidanius, J., Pratto, F., Kteily, N., ... Dover, T. (2012). Assimilation, multiculturalism, and colourblindness: Mediated and moderated relationships between social dominance orientation and prejudice. Journal of Experimental Social Psychology, 48, 207-212.

Lolliot, S. D., Schmid, K., Hewstone, M., Al Ramiah, A., Tausch, N., \& Swart, H. (2013). Generalized effects of intergroup contact: The secondary transfer effect. In G. Hodson \& M. Hewstone (Eds.), Advances in intergroup contact (pp. 81-112). London, UK: Psychology Press.

Miles, E., \& Crisp, R. J. (2014). A meta-analytic test of the imagined contact hypothesis. Group Processes \& Intergroup Relations, 17, 3-26.

Miller, N. (2002). Personalisation and the promise of contact theory. Journal of Social Issues, 58, $387-410$.

Morrison, K. R., Plaut, V. C., \& Ybarra, O. (2010). Predicting whether multiculturalism positively or negatively influences White Americans' intergroup attitudes: The role of ethnic identification. Personality and Social Psychology Bulletin, 36, 1648-1661.

Pagotto, L., Visintin, E. P., De Iorio, G., \& Voci, A. (2013). Imagined intergroup contact promotes cooperation through outgroup trust. Group Processes \& Intergroup Relations, 16, 209-216.

Park, B., \& Judd, C. M. (2005). Rethinking the link between categorisation and prejudice within the social cognition perspective. Personality and Social Psychology Review, 9, 108-130.

Pettigrew, T. F. (2009). Secondary transfer effect of contact: Do intergroup contact effects spread to noncontacted outgroups? Social Psychology, 40, 55-65.

Pettigrew, T. F., \& Tropp, L. R. (2011). When groups meet: The dynamics of intergroup contact. Essays in Social Psychology series. New York, NY: Psychology Press.

Plaut, V. C. (2010). Diversity science: Why and how difference makes a difference. Psychological Inquiry, 21, 77-99. 
Richards, Z., \& Hewstone, M. (2001). Subtyping and subgrouping: Processes for the prevention and promotion of stereotype change. Personality and Social Psychology Review, 5, 52-73.

Richeson, J. A., \& Nussbaum, R. J. (2004). The impact of multiculturalism versus colourblindness on racial bias. Journal of Experimental Social Psychology, 40, 417-423.

Rosenthal, L., \& Levy, S. R. (2010). The colorblind, multicultural, and polycultural ideological approaches to improving intergroup attitudes and relations. Social Issues and Policy Review, 4, 215-246.

Sasaki, S. J., \& Vorauer, J. D. (2013). Ignoring versus exploring differences between groups: Effects of salient colourblindness and multiculturalism on intergroup attitudes and behaviour. Social and Personality Psychology Compass, 7, 246-259.

Sidanius, J., \& Pratto, F. (1999). Social dominance: An intergroup theory of social hierarchy and oppression. Cambridge, UK: Cambridge University Press.

Siy, J. O., \& Cheryan, S. (2016). Prejudice masquerading as praise: The negative echo of positive stereotypes. Personality and Social Psychology Bulletin, 42, 941-954.

Stathi, S., Crisp, R. J., \& Hogg, M. A. (2011). Imagining intergroup contact enables member-togroup generalization. Group Dynamics: Theory, Research, and Practice, 15, 275-284.

Stathi, S., Tsantila, K., \& Crisp, R. J. (2012). Imagining intergroup contact can combat mental health stigma by reducing anxiety, avoidance and negative stereotyping. Journal of Social Psychology, 152, 746-757.

Tausch, N., Hewstone, M., Kenworthy, J. B., Psaltis, C., Schmid, K., Popan, J. R., . . Hughes, J. (2010). Secondary transfer effects of intergroup contact: Alternative accounts and underlying processes. Journal of Personality and Social Psychology, 99, 282-302.

Verkuyten, M. (2005). Ethnic group identification and group evaluation among minority and majority groups: Testing the multiculturalism hypothesis. Journal of Personality and Social Psychology, 88, 121-138. 
Vezzali, L., Capozza, D., Giovannini, D., \& Stathi, S. (2012). Improving implicit and explicit intergroup attitudes using imagined contact: An experimental intervention with elementary school children. Group Processes \& Intergroup Relations, 15, 203-212.

Vorauer, J. D., Gagnon, A., \& Sasaki, S. J. (2009). Salient intergroup ideology and intergroup interaction. Psychological Science, 20, 838-845.

West, K., Holmes, E., \& Hewstone, M. (2011). Enhancing imagined contact to reduce prejudice against people with schizophrenia. Group Processes \& Intergroup Relations, 14, 407-428.

Wolsko, C., Park, B., Judd, C. M., \& Wittenbrink, B. (2000). Framing interethnic ideology: Effects of multicultural and color-blind perspectives on judgments of groups and individuals. Journal of Personality and Social Psychology, 78, 635-654. 
Table 1

Means (and Standard Deviations) of Warmth and Competence Perceptions for Each Group as a

Function of the Experimental Conditions.

\begin{tabular}{llll}
\hline \multicolumn{4}{c}{ Experimental conditions } \\
\hline \multicolumn{2}{c}{ Colorblindness } & \multicolumn{2}{c}{ Multiculturalism } \\
\hline Typical & Atypical & Typical & $\begin{array}{c}\text { Atypical } \\
(n=20)\end{array}$ \\
$(n=20)$ & $(n=20)$ & $(n=16)$ & $(n=10)$
\end{tabular}

Target outgroup

\begin{tabular}{|c|c|c|c|c|c|}
\hline \multirow{2}{*}{ British muslims } & Warmth & $5.63(1.18)$ & $5.43(1.21)$ & $5.44(1.35)$ & $5.08(1.09)$ \\
\hline & Competence & $5.73(1.07)$ & $5.77(0.92)$ & $6.06(0.69)$ & $5.18(1.13)$ \\
\hline \multirow{2}{*}{ Moroccans } & Warmth & $5.58(0.96)$ & $5.70(0.95)$ & $6.00(0.82)$ & $5.00(1.04)$ \\
\hline & Competence & $5.65(1.07)$ & $5.77(0.83)$ & $5.96(0.91)$ & $5.08(1.15)$ \\
\hline \multirow{2}{*}{$\begin{array}{l}\text { Physically } \\
\text { disabled people }\end{array}$} & Warmth & $5.75(0.90)$ & $5.77(1.08)$ & $5.85(0.89)$ & $5.02(1.10)$ \\
\hline & Competence & $5.53(0.92)$ & $5.28(1.20)$ & $5.21(1.00)$ & $4.83(1.04)$ \\
\hline \multirow{2}{*}{ Asians } & Warmth & $5.42(1.18)$ & $5.65(0.99)$ & $5.62(1.35)$ & $5.03(1.22)$ \\
\hline & Competence & $5.87(1.07)$ & $6.03(0.94)$ & $6.19(0.77)$ & $5.33(1.16)$ \\
\hline \multirow{2}{*}{$\begin{array}{l}\text { People with } \\
\text { Schizophrenia }\end{array}$} & Warmth & $4.98(1.07)$ & $4.98(1.34)$ & $5.14(1.45)$ & $4.77(1.36)$ \\
\hline & Competence & $5.17(1.06)$ & $4.78(1.40)$ & $4.94(1.16)$ & $4.63(1.17)$ \\
\hline
\end{tabular}

